\title{
Determination of CYP2D6 *3, *4, and *10 frequency in women with breast cancer in São Luís, Brazil, and its association with prognostic factors and disease-free survival
}

\author{
D.M.F. Martins ${ }^{1}$, F.C.B. Vidal ${ }^{2}$, R.D.M. Souza ${ }^{3}$, S.A. Brusaca ${ }^{3}$ and L.M.O. Brito ${ }^{2,4}$ \\ ${ }^{1}$ Instituto Maranhense de Oncologia Aldenora Bello, São Luís, MA, Brasil \\ ${ }^{2}$ Banco de Tumores e DNA do Maranhão, Universidade Federal do Maranhão, São Luís, MA, Brasil \\ ${ }^{3}$ Escola de Medicina, Universidade Federal do Maranhão, São Luís, MA, Brasil \\ ${ }^{4}$ Departamento de Medicina III, Universidade Federal do Maranhão, São Luís, MA, Brasil
}

\begin{abstract}
The CYP2D6 enzyme is crucial for the metabolism of tamoxifen. The CYP2D6 gene is highly polymorphic, and individuals can be extensive, intermediate, or poor tamoxifen metabolizers. The aim of this study was to determine the frequencies of the CYP2D6 *3, *4, and *10 alleles in women with breast cancer who were treated with tamoxifen and analyze the association of enzyme activity with prognostic factors and disease-free survival. We observed a high frequency of CYP2D6 ${ }^{*} 10$, with an allelic frequency of $0.14(14.4 \%)$. The *3 allele was not present in the studied population, and * 4 had an allelic frequency of 0.13 (13.8\%). We conclude that patients with reduced CYP2D6 activity did not present worse tumor characteristics or decreased disease-free survival than women with normal enzyme activity, as the difference was not statistically significant. We also observed a high frequency of CYP2D6 ${ }^{*} 10$, which had not been previously described in this specific population. This study is the first in north-northeastern Brazil that aimed to contribute to the knowledge of the Brazilian regional profile for CYP2D6 polymorphisms and their phenotypes. These findings add to the knowledge of the distribution of different polymorphic CYP2D6 alleles and the potential role of CYP2D6 genotyping in clinical practice prior to choosing therapeutic protocols.
\end{abstract}

Key words: Tamoxifen; Cytochrome P450 2D6; Breast cancer; Genetic polymorphisms; Prognostic factors; Disease-free survival

\section{Introduction}

Cytochrome P450 is involved in the metabolism of many drugs, including antidepressants, $\beta$-blockers, antiarrhythmics, antihypertensives, opioids, antipsychotics, and antineoplastics (1). The gene encoding the enzyme is highly polymorphic and is represented by more than 100 different, previously described alleles.

Tamoxifen (TMX), a selective modulator of the estrogen receptor $(E R)$, has been considered the gold standard endocrine treatment of breast cancer $(\mathrm{BC})$ for more than three decades (2). It is used as an adjuvant endocrine therapy in women with ER-positive breast tumors for treatment of pre- and post-menopausal women with metastatic BC, chemoprevention in high-risk women, and treatment of women with in situ ductal carcinoma (3). The clinical outcomes resulting from TMX treatment are influenced by several factors, including activity of the cytochrome P450 enzyme, patient adherence to treatment, use of comedications that can inhibit conversion of TMX into active metabolites, and other mechanisms of molecular resistance (4).

TMX is a prodrug that requires metabolic activation to perform its pharmacological activity (5). TMX biotransformation is dependent on the 2D6 subunit of cytochrome P450 (CYP2D6), which initiates demethylation and hydroxylation and thereby generates various metabolites, mainly $4-\mathrm{OH}$ tamoxifen, alpha-OH-tamoxifen, $\mathrm{N}$-desmethyl-tamoxifen,

Correspondence: F.C.B. Vidal, Banco de Tumores e DNA do Maranhão, Universidade Federal do Maranhão, Rua Coelho Neto, 311, 65020-140 São Luís, MA, Brasil. E-mail: flavidal@hotmail.com 
and 4-OH-N-desmethyl-tamoxifen (6). These metabolites compete with endogenous estrogen by binding to the ER. 4-OH-tamoxifen and 4-OH-N-desmethyl-tamoxifen (endoxifen), in particular, have a high affinity for the ER. Endoxifen is considered the primary active metabolite of TMX because it has a 100-times greater affinity for ER than TMX and is 3-10 times more potent in suppressing cell proliferation (7). Polymorphism of the gene that encodes the CYP2D6 enzyme may increase or decrease the enzyme's metabolic activity. Accordingly, these polymorphisms may result in lower levels of active TMX metabolites, which may result in decreased therapeutic response to TMX. In fact, endoxifen plasma concentration has a high inter-individual variability, which has been described in patients with $\mathrm{BC}(8,9)$.

Four phenotypic categories have been assigned to individuals according to enzyme function: poor metabolizer (PM), intermediate metabolizer (IM), extensive metabolizer (EM), and ultra-fast metabolizer $(10,11)$. Individuals with two PM alleles are classified as poor metabolizers. Individuals with the genotypes EM/PM, EM/IM, or EM/EM have normal metabolism and are classified as extensive metabolizers. The genotypes IM/IM or IM/PM have enzymatic activity ranging between extensive and poor and are referred to as intermediate metabolizers $(10,12)$. Patients classified as PM (PM/PM) present with low endoxifen plasma levels and poor clinical outcomes when treated with $\operatorname{TMX}(11,13,14)$.

Approximately $5-10 \%$ of Caucasians are carriers of two null alleles (PM), with a total frequency of $26 \%$. The most common PM allele in this ethnic group is CYP2D6*4, which is responsible for $75 \%$ of European PMs (15). Other null alleles, also present in Caucasians, are represented by the polymorphic alleles *3, *5, and *6 (16). In African-Americans and Asians, the most common non-functioning variant is the *5 allele, present in at least $6 \%$ of the population (17).

The IM phenotype is caused mainly by the presence of the polymorphic allele ${ }^{*} 10$. The frequency of this allele is higher in eastern Asian groups (China, 56\%; Korea, 45\%; and Japan, 38\%) (16) than in Europeans $(<2 \%)$. In the African population, the polymorphic allele $* 17$ is the main cause of the IM phenotype, and it occurs in moderate to high frequencies $(9-34 \%)$. Another IM allele, CYP2D6*29, is found at a relatively high frequency in a population in Tanzania (20\%) (15).

Studies conducted worldwide offer strong evidence of the effectiveness of TMX for BC treatment; however, clinical outcomes depend on bioactivation of the drug by the CYP2D6 enzyme and on its pharmacological interactions. In addition, the use of an individualized genetic approach to hormone therapy is a promising option for the improvement of BC treatment.

In Brazil, the frequencies of the various CYP2D6 alleles are poorly known. In this study, we determined the frequencies of CYP2D $6{ }^{*} 3$, * 4 , and *10 alleles in women with $\mathrm{BC}$ who were treated with tamoxifen, and analyzed associations of enzyme activity with prognostic factors and disease-free survival (DFS).

\section{Material and Methods}

\section{Patients and study design}

This was a cross-sectional study for determination of allele frequency, and a cohort study to determine DFS. The study population included women diagnosed with stage I-III infiltrating breast adenocarcinoma who were treated with adjuvant TMX for at least 24 months and had tumors positive for ER and/or progesterone receptor (PR). Women were invited to participate in this study by their clinical oncologist when they attended medical visits. Written informed consent was obtained from all participants, and after signing, a blood sample was collected from each participant by a trained professional. The study was conducted from August 2011 to December 2012 at the oncology outpatient clinic of the Maranhense Institute of Oncology Aldenora Bello. The study was approved by the Ethics Committee of the University Hospital of the Federal University of Maranhão, under protocol number 100/11 and in accordance with resolution 196/96 of the National Health Council.

Women diagnosed with ER- and/or PR-positive, infiltrating grade I, II and III carcinoma treated with tamoxifen for at least 24 months were eligible for inclusion. Exclusion criteria were metastatic BC, HIV positivity, patients with serious comorbidities, or patients who refused to participate in this study.

\section{Genetic analysis of polymorphisms}

DNA was extracted from peripheral venous blood samples using QIAmp ${ }^{\mathbb{R}}$ DNA Mini and Blood Mini kits (Qiagen, USA), according to the manufacturer's protocols. The extracted DNA was stored at the Maranhão Tumor Bank at $-80^{\circ} \mathrm{C}$. Presence of the CYP2D6*3, CYP2D6*4, and $C Y P 2 D 6{ }^{*} 10$ polymorphisms were investigated by $P C R$ and restriction enzyme digestion, using 100 ng DNA as a template, as described previously by Schur et al. (18) and Kiyotani et al. (19).

\section{Database and statistical analysis}

Statistical analysis was performed using Epi Info software, version 3.5.2 (Centers for Disease Control, USA). The clinical, sociodemographic, and treatment data were obtained from medical records and through interviews; these data were stored in protocol files and in a computerized database for statistical analysis. The CYP2D6 genotype categories were classified according to the phenotypes cited above for the CYP2D6 combined analyses. DFS was estimated using the Kaplan-Meier method and defined as the period between diagnosis and local or distant recurrence. The Kaplan-Meier curves demonstrate the estimated survival of patients with normal CYP2D6 and with reduced CYP2D6 enzyme activity. The mean follow-up time was 73 months. The survival curves calculated for phenotypic groups were compared using the log-rank test. P-values $<0.05$ were considered to be statistically significant. Fisher's exact test was used for frequency analysis; odds ratios 
Table 1. General characteristics of the 58 women included in the study.

\begin{tabular}{|c|c|c|}
\hline Characteristics & $\mathrm{n}$ & $\%$ \\
\hline \multicolumn{3}{|l|}{ Age at diagnosis } \\
\hline $20-29$ & 1 & 1.7 \\
\hline $30-39$ & 16 & 27.6 \\
\hline $40-49$ & 17 & 29.3 \\
\hline $50-59$ & 8 & 13.8 \\
\hline $60-69$ & 13 & 22.4 \\
\hline$\geq 70$ & 3 & 5.2 \\
\hline \multicolumn{3}{|l|}{ Marital status } \\
\hline Married & 26 & 44.8 \\
\hline Single & 21 & 36.2 \\
\hline Consensual union & 1 & 1.7 \\
\hline Widow & 10 & 17.2 \\
\hline \multicolumn{3}{|l|}{ Self-reported ethnicity } \\
\hline Caucasian & 18 & 31.0 \\
\hline Mullato & 27 & 46.6 \\
\hline Black & 13 & 22.4 \\
\hline \multicolumn{3}{|l|}{ Education levels } \\
\hline Illiterate & 10 & 17.2 \\
\hline High school graduate or less & 38 & 63.8 \\
\hline College graduate & 11 & 19.0 \\
\hline \multicolumn{3}{|l|}{ Number of pregnancies } \\
\hline 0 & 5 & 8.6 \\
\hline$\geq 1$ & 53 & 91.4 \\
\hline \multicolumn{3}{|l|}{ Age at menarche } \\
\hline 11 years & 9 & 15.5 \\
\hline $12-13$ years & 30 & 51.7 \\
\hline$\geq 14$ years & 19 & 32.7 \\
\hline
\end{tabular}

(ORs) and 95\% confidence intervals (Cls) were calculated to estimate associations between phenotype and disease recurrence or distant metastasis.

\section{Results}

\section{Characteristics of patients}

A total of 58 women with BC who fulfilled the inclusion criteria were evaluated. Epidemiological profiles are listed in Table 1. Most patients (58.6\%) were $\leq 50$ years of age, married $(44.8 \%)$, and predominantly of brown skin color (46.6\%). A total of $44.8 \%$ of patients completed at least high school, $17.2 \%$ were illiterate, and $38 \%$ had completed elementary school. The average number of pregnancies per woman was 3.6; five women $(8.6 \%)$ were nulliparous. The majority of these women $(51.7 \%)$ had their menarche between 12 and 13 years of age.

Forty-seven percent of patients had not reached menopause at the time of BC diagnosis. Twenty-five patients $(43.1 \%)$ reported previous use of hormonal contraceptives, and $23(39.6 \%)$ reported use of hormone replacement therapy. Only one patient presented with a previous history of cancer. Two cases presented with metachronous second primary tumors: one with contralateral $\mathrm{BC}$ and one with thyroid cancer. Twenty-eight patients $(48.2 \%)$ reported a family history of cancer with at least one case of cancer in first- and second-degree relatives.

Table 2 describes the clinical characteristics and immune histopathological profiles of tumors and treatments. Initial staging was established at diagnosis in more than $70 \%$ of the patients. "Moderately differentiated" was the predominant histological grade (75.9\%).

Expression of human epidermal growth factor receptor 2 (HER2), which is associated with tumor aggressiveness, was observed in $17.2 \%$ of cases. The right breast was more commonly affected $(60.3 \%)$ than the left; one case of bilateralism was observed $(1.7 \%)$. Tumor sizes between 2 and $5 \mathrm{~cm}$ were observed in most cases $(39.7 \%)$. Compromised lymph nodes were observed in more than half of the patients (53.3\%). More than $80 \%$ of the patients were given radiation therapy and chemotherapy, and all, except one who refused, underwent tumor excision.

\section{Frequency of CYP2D6 alleles and genotypes}

Three different CYP2D 6 gene polymorphic alleles were investigated: two alleles with null enzymatic activity ( $\left.{ }^{*} 3,{ }^{*} 4\right)$ and one with reduced activity $\left({ }^{*} 10\right)$. Table 3 shows the observed allelic frequencies and genotype distribution for the CYP2D6 gene. The polymorphic allele * 4 was present in $25.8 \%$ of the studied population, with a frequency of 0.13 (13.8\%). The polymorphic allele * 10 was detected in $24.1 \%$ of the patients, with a frequency of $0.14(14.4 \%)$. The *3 allele was not present in the studied population. Most patients $(73.1 \%)$ did not have any of these polymorphic alleles and had a genotype corresponding to the wild-type (wt). The * 4 allele was heterozygous in 14 patients and homozygous in one patient. The *10 allele was heterozygous in 11 patients and homozygous in three patients. The most frequent genotype was wt/wt (65.5\%), followed by ${ }^{*} 4{ }^{*} 10(15.5 \%)$. Most of the women in the study $(77.5 \%)$ presented with the EM phenotype, followed by IM (20.7\%), and PM (1.7\%).

Some classic prognostic factors of BC found in the study population, such as tumor size, histologic grade, lymph node status and expression of HER-2, are reported in Table 4. There was no association between tumor characteristics with a worse prognosis and reduced CYP2D6 activity as this difference was not statistically significant. The only PM patient presented with a tumor larger than $2 \mathrm{~cm}$, with moderately differentiated histology, positive lymph nodes, and positive HER2 expression.

Polymorphic alleles were not identified $\left({ }^{*} 3 /{ }^{*} 4 /{ }^{*} 10\right)$ in patients of black skin color; all presented with the wt/wt genotype and normal enzyme activity. The reduced function genotypes, IM and PM, were more frequently observed in white women $(33.3 \%)$ than in women of brown skin color $(25.9 \%)$ or women of black skin color $(P=0.07)$. The *10 allelic frequency was higher in women of brown skin color than in the other groups $(0.18)$ (Table 5$)$. 
Table 2. Clinical features, tumor characteristics, and treatment of patients.

\begin{tabular}{|c|c|c|}
\hline Characteristics & $\mathrm{n}$ & $\%$ \\
\hline \multicolumn{3}{|l|}{ Clinical stage } \\
\hline 1 & 12 & 20.7 \\
\hline IIA & 15 & 25.9 \\
\hline IIB & 14 & 24.1 \\
\hline IIIA & 11 & 19.0 \\
\hline IIIB & 2 & 3.4 \\
\hline IIIC & 4 & 6.9 \\
\hline \multicolumn{3}{|l|}{ Histologic grade } \\
\hline Well differentiated & 6 & 10.3 \\
\hline Moderately differentiated & 44 & 75.9 \\
\hline Poorly differentiated & 4 & 6.9 \\
\hline Uninformed & 4 & 6.9 \\
\hline \multicolumn{3}{|l|}{ Receptors status } \\
\hline $\mathrm{ER}+$ & 54 & 93.1 \\
\hline $\mathrm{PR}+$ & 47 & 81.0 \\
\hline HER2 + & 10 & 17.2 \\
\hline \multicolumn{3}{|l|}{ Laterality } \\
\hline Right & 35 & 60.3 \\
\hline Left & 22 & 37.9 \\
\hline Bilateral & 1 & 1.7 \\
\hline \multicolumn{3}{|l|}{ Tumor size $(\mathrm{cm})$} \\
\hline$<2$ & 18 & 31.0 \\
\hline $2-5$ & 23 & 39.7 \\
\hline$>5$ & 9 & 15.5 \\
\hline Uninformed & 8 & 13.8 \\
\hline \multicolumn{3}{|l|}{ Lymph node status } \\
\hline 0 & 25 & 43.1 \\
\hline $1-3$ & 17 & 29.3 \\
\hline $4-9$ & 11 & 18.9 \\
\hline$\geq 10$ & 3 & 5.1 \\
\hline Uninformed & 2 & 3.5 \\
\hline \multicolumn{3}{|l|}{ Radiotherapy } \\
\hline Yes & 52 & 89.7 \\
\hline No & 6 & 10.3 \\
\hline \multicolumn{3}{|l|}{ Chemotherapy } \\
\hline Yes & 47 & 81.0 \\
\hline No & 11 & 19.0 \\
\hline \multicolumn{3}{|l|}{ Surgery } \\
\hline No & 1 & 1.7 \\
\hline Setorectomy & 1 & 1.7 \\
\hline Quadrantectomy with axillary dissection & 22 & 38.4 \\
\hline Simple mastectomy & 6 & 10.3 \\
\hline $\begin{array}{l}\text { Modified mastectomy with axillary } \\
\text { lymphadenectomy }\end{array}$ & 28 & 49.1 \\
\hline
\end{tabular}

$\mathrm{ER}+$ : positive estrogen receptor; $\mathrm{PR}+$ : positive progesterone receptor; HER2 +: positive for human epidermal growth factor receptor 2 .

\section{Enzyme activity and disease-free survival}

The study results demonstrated that patients with reduced enzyme activity did not have shorter DFS than
Table 3. Allele and genotypic frequency and distribution of CYP2D6.

\begin{tabular}{lclc}
\hline Alleles & $\mathrm{n}(\%)$ & Enzyme activity & $\begin{array}{c}\text { Allele } \\
\text { frequency (\%) }\end{array}$ \\
\hline CYP2D6* $w t$ & $45(77.5)$ & Functional & 73.1 \\
CYP2D6*3 & 0 & Non-functional & 0 \\
CYP2D6*4 & $15(25.8)$ & Non-functional & 13.8 \\
CYP2D6*10 & $14(24.1)$ & Dysfunctional & 14.4 \\
\hline Genotype & $\mathrm{n}$ & Phenotype & $\%$ \\
\hline$w t / w t$ & 38 & EM homozygous & 65.5 \\
$w t /{ }^{*} 4$ & 5 & EM heterozygous & 8.6 \\
$w t /{ }^{*} 10$ & 2 & EM heterozygous & 3.4 \\
${ }^{*} 4 /{ }^{*} 10$ & 9 & IM heterozygous & 15.5 \\
${ }^{*} 10 /{ }^{*} 10$ & 3 & IM homozygous & 5.2 \\
${ }^{*} 4 /{ }^{*} 4$ & 1 & PM & 1.7 \\
\hline
\end{tabular}

wt: wild type; EM: extensive metabolizer; IM: intermediate metabolizer; PM: poor metabolizer. Fisher's test was used for frequency analysis.

women with normal CYP2D6 activity (log-rank test, $P=0.75$; Figure 1). The only patient classified as PM did not have local or distant recurrence; however, her use of TMX was interrupted due to endometrial thickening.

\section{Discussion}

The association between CYP2D6 enzyme activity phenotypes and successful treatment of BC with TMX is still uncertain. Some studies have shown strong evidence that the effectiveness of TMX treatment for hormone receptorpositive breast tumors depends on CYP2D6 hepatic enzyme metabolism $(5,7-10,20)$. These studies indicate that women with $\mathrm{BC}$ who are carriers of one or more alleles that result in decreased CYP2D6 function, or those who use potent enzyme inhibitors, such as fluoxetine and paroxetine, have inferior therapy outcomes than women with normal CYP2D6 enzyme function. In those cases, genetic testing might be useful to predict the benefit of TMX therapy.

Conversely, some authors report the lack of an association between enzyme genotype and clinical response in women treated with TMX (9,11-13). Two studies conducted in Sweden report an association between the polymorphic allele * 4 and better clinical response in patients treated with TMX $(11,21)$. In addition, Japanese researchers demonstrated that the clinical response of women with the polymorphic allele * 10 were not significantly different from those observed in women with a normal phenotype $(12,13)$.

In the present study, patients who were carriers of the polymorphic alleles * 4 and ${ }^{*} 10$, corresponding to the IM and PM phenotypes, respectively, did not have a shorter DFS than women with normal CYP2D6 activity, and did not 
Table 4. Association between the CYP2D6 *10 genotype and patient characteristics.

\begin{tabular}{|c|c|c|c|c|c|}
\hline Characteristics & $\mathrm{n}$ & CYP2D6 normal activity & CYP2D6 reduced activity & $\mathrm{P}$ & OR $(95 \% \mathrm{Cl})$ \\
\hline Patients & 58 & $45(77.6)$ & $13(22.4)$ & & \\
\hline Tumor size $(\mathrm{cm})$ & & & & 0.33 & $1.6(0.4-6.3)$ \\
\hline$\leq 2 \mathrm{~cm}$ & 24 & $20(45.5)$ & $4(33.3)$ & & \\
\hline$>2 \mathrm{~cm}$ & 32 & $24(54.5)$ & $8(66.7)$ & & \\
\hline Uninformed & 2 & & & & \\
\hline Histologic grade & & & & 0.26 & - \\
\hline Well differentiated & 6 & $6(13.3)$ & 0 & & \\
\hline Moderately differentiated & 44 & $34(75.5)$ & $10(100)$ & & \\
\hline Poorly differentiated & 4 & $4(8.8)$ & 0 & & \\
\hline Uninformed & 4 & & & & \\
\hline Lymph node status & & & & 0.28 & $1.8(0.4-6.9)$ \\
\hline Negative & 25 & $21(47.7)$ & $4(33.3)$ & & \\
\hline Positive & 31 & $23(52.3)$ & $8(66.7)$ & & \\
\hline Uninformed & 2 & & & & \\
\hline Her2 status & & & & 0.69 & $1.83(0.3-8.9)$ \\
\hline Negative & 37 & $30(66.7)$ & $7(53.8)$ & & \\
\hline Positive & 10 & $7(15.6)$ & $3(23.1)$ & & \\
\hline Uninformed & 11 & & & & \\
\hline
\end{tabular}

Odds ratios and $95 \%$ confidence intervals were calculated to estimate associations between phenotype and disease recurrence or distant metastasis. No statistically significant differences were observed $(P>0.05)$.

present worse tumor characteristics compared with those of women having normal enzymatic activity. Thus, CYP2D6 polymorphisms would not seem to be a prognostic factor in $\mathrm{BC}$ and are not predictive factors of response to TMX treatment. However, this study sample was small, and therefore the results should be analyzed with caution.

Okishiro et al. (12) also observed that genetic polymorphisms of CYP2D6*10 were not associated with prognosis, endometrial thickness, or bone mineral density in Japanese BC patients treated with adjuvant tamoxifen. Park et al. (22) found no significant association with any of the CYP2D6 genetic variants and prognostic factors, including tumor size, nodal status, Ki67, PR negativity, and HER2 positivity.

Table 5. Association between the CYP2D6 genotype and phenotype according to patient self-reported ethnicity.

\begin{tabular}{|c|c|c|c|c|}
\hline \multirow[t]{2}{*}{ Characteristics } & \multicolumn{3}{|c|}{ Self-reported ethnicity (n, \%) } & \multirow[t]{2}{*}{$\mathrm{P}$} \\
\hline & Caucasian $(n=18)$ & Mullato $(n=27)$ & Black $(n=13)$ & \\
\hline Genotype & & & & 0.17 \\
\hline$w t / w t$ & $11(61.1)$ & $14(51.9)$ & $13(100)$ & \\
\hline$w t /{ }^{*} 4$ & $1(5.6)$ & $4(14.8)$ & 0 & \\
\hline$w t /{ }^{*} 10$ & 0 & $2(7.4)$ & 0 & \\
\hline${ }^{*} 4 /{ }^{*} 10$ & $5(27.8)$ & $4(14.8)$ & 0 & \\
\hline *10/*10 & $1(5.6)$ & $2(7.4)$ & 0 & \\
\hline${ }^{*} 4 /{ }^{*} 4$ & 0 & $1(3.7)$ & 0 & \\
\hline Phenotype & & & & 0.07 \\
\hline Normal activity & $12(66.7)$ & $20(74.1)$ & $13(100)$ & \\
\hline Reduced activity & $6(33.3)$ & $7(25.9)$ & 0 & \\
\hline Allele frequency & & & & - \\
\hline *3 & 0 & 0 & 0 & \\
\hline *4 & 0.16 & 0.18 & 0 & \\
\hline *10 & 0.16 & 0.18 & 0 & \\
\hline
\end{tabular}

Odds ratios and $95 \%$ confidence intervals were calculated to estimate associations between phenotype and disease recurrence or distant metastasis. wt: wild type. No statistically significant differences were observed $(P>0.05)$. 


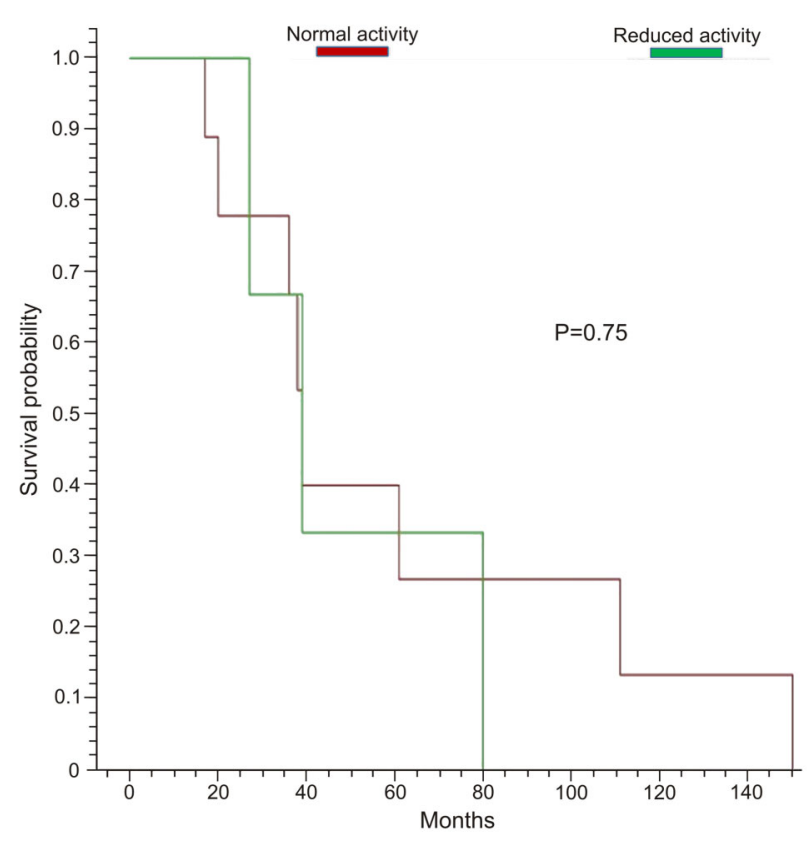

Figure 1. Disease-free survival was estimated using the KaplanMeier method and defined as the period between diagnosis and local or distant recurrence. Survival curves between phenotypic groups were compared using the log-rank test. $P=0.75$, not statistically significant.

This study is the first in north-northeastern Brazil that aimed to contribute to the knowledge of the Brazilian regional profile of CYP2D6 polymorphisms and their phenotypes. Other studies have been performed addressing this subject in southern and southeastern regions of Brazil. Jardim et al. (14) evaluated the presence of the polymorphic alleles ${ }^{*} 3,{ }^{*} 4,{ }^{*} 5,{ }^{*} 6$, and ${ }^{*} 10$, in addition to the phenotypes of TMX metabolism, in 30 patients from southeastern Brazil. They reported allelic frequencies of $33 \%$ and $38 \%$ for the polymorphic alleles ${ }^{*} 4$ and ${ }^{*} 10$, respectively. The polymorphic alleles ${ }^{*} 5$ and ${ }^{*} 6$ were found to be heterozygous in only one patient, and allele * 3 was not present in the studied population. Our results are similar to those of Jardim et al. (14); allele *10 was observed at higher frequencies than allele * 4 , and allele ${ }^{*} 3$ was not observed.

Another Brazilian study, published by Antunes et al. (15), evaluated the relationship between CYP2D 6 genotypes and phenotypes and serum levels of endoxifen in 97 patients with $\mathrm{BC}$ from the southern region of the country. Sixteen alleles were studied $\left({ }^{*} 1,{ }^{*} 2,{ }^{*} 3,{ }^{*} 4,{ }^{*} 5,{ }^{*} 6,{ }^{*} 7,{ }^{*} 8,{ }^{*} 9,{ }^{*} 10,{ }^{*} 11\right.$, ${ }^{*} 15,{ }^{*} 17,{ }^{*} 29,{ }^{*} 35$, and ${ }^{*} 41$ ); the authors reported allelic frequencies of $2 \%, 18.1 \%$, and $1 \%$ for the polymorphic alleles *3, *4, and *10, respectively, and the distribution of phenotypes was $88.7 \%$ for $\mathrm{EM}, 4.1 \%$ for $\mathrm{IM}$, and $4.1 \%$ for PM.

The frequency observed for the *10 allele in this study was surprisingly high, considering that this allele occurs with greater frequency in eastern Asian populations (China,
0.56; Korea, 0.45; and Japan, 0.38) (16) than its frequency in African-Americans (0.06), Ethiopians (0.03-0.09), and Europeans $(<0.02)(17)$. This reflects the importance of the presence of Asian people in our sample, which may be a result of miscegenation with Amerindians who, according to historical evidence, originated in Asia (23-25). Therefore, the frequency distribution of CYP2D6 alleles in southern Amerindians might be expected to be similar to that of Asian populations. Jorge et al. (26) reported results from a study including Ngawbe and Embera Amerindians from Panama and Colombia, which were similar to our results. They found a high frequency of the ${ }^{*} 10$ allele $(6.9$ and $14 \%$, respectively) and an absence of the *3 allele, which is rare in Asians.

The frequency of the * 4 allele (13.5\%) observed in this study was similar to that found in European populations (17.5-23\%) (6) and other Latin American populations, such as those from Colombia (19.4\%) (27), Venezuela (13.4\%) and Mexico (1.2-7.3\%) (28). In contrast, the allelic frequency of * 4 reported in this study was higher than that found in Asian populations (0-1\%) (29).

Evaluation of the relationships between phenotypic presentation stratified by skin color and allele frequencies showed that the * 4 allele was more frequent in women of brown skin color (0.18), although these patients were largely heterozygous $\left(w t /{ }^{*} 4\right)$ and carriers of one wt allele (14.8\%), and thus had normal enzyme activity. Nonetheless, Silveira et al. (30) reported an increased frequency of the * 4 allele in white individuals $(0.14)$ compared with those with black and brown skin color (0.10) in a study of 364 Brazilians who were not oncology patients. In our study, white women had higher percentages of reduced function genotypes (33.3\%), IM and PM, than women of brown (25.9\%) and black skin color $(P=0.07)$, when grouped by metabolic phenotypes. The absence of the studied polymorphic alleles in black women was a relevant finding, which could be explained by the low frequency of these alleles in African populations. In these populations, the dysfunctional *17 allele is dominant, and higher frequencies (16 to $26 \%$ ) are observed (31). Hence, although the *17 allele was not included in this study, it may have an important representation in the population of the state of Maranhão because of the presence of quilombola communities including descendants of Afro-Brazilian slaves.

In conclusion, the results obtained in the present study demonstrated the existence of genetic polymorphisms in the gene encoding the CYP2D6 enzyme in a population of women with $\mathrm{BC}$. The results emphasized the frequency of the ${ }^{*} 10$ allele $(14.4 \%)$ and a significant percentage of women with reduced CYP2D6 activity (22.4\%). These results highlight the important regional variability of allelic frequencies in this Brazilian population, characterized by various patterns of miscegenation. These results also reflect the importance of the Asian and Caucasian origins of this population of predominantly European origin, reflected by the frequency of the * 4 allele, and of Asian origin, reflected by the frequency of the ${ }^{*} 10$ allele; both 
alleles were observed in $15.5 \%$ of patients. These findings contribute to the knowledge about the distribution of different polymorphic CYP2D6 alleles in the Brazilian population and the potential role of CYP2D 6 genotyping in clinical practice prior to deciding on therapeutic protocols.

The individual optimization of $\mathrm{BC}$ treatment is an ongoing goal of oncology research. According to data reported in the literature and the results obtained in the present study, patients with low CYP2D6 enzyme activity do not receive the expected benefits of TMX treatment, and therefore may be candidates for other therapies. Hence, other studies in this area are necessary to elucidate and

\section{References}

1. Lewis DF. 57 varieties: the human cytochromes P450. Pharmacogenomics 2004; 5: 305-318, doi: 10.1517/phgs.5.3. 305.29827.

2. Higgins MJ, Stearns V. Pharmacogenetics of endocrine therapy for breast cancer. Annu Rev Med 2011; 62: 281293, doi: 10.1146/annurev-med-070909-182545.

3. Singh MS, Francis PA, Michael M. Tamoxifen, cytochrome P450 genes and breast cancer clinical outcomes. Breast 2011; 20: 111-118, doi: 10.1016/j.breast.2010.11.003.

4. Souza RDM, Chein MBC, Brito LMO. Importância do CYP2D6 em usuárias de tamoxifeno no câncer de mama. Femina 2011; 39: 8.

5. Jin Y, Desta Z, Stearns V, Ward B, Ho H, Lee KH, et al. CYP2D6 genotype, antidepressant use, and tamoxifen metabolism during adjuvant breast cancer treatment. $J$ Natl Cancer Inst 2005; 97: 30-39, doi: 10.1093/jnci/dji005.

6. Kiyotani K, Mushiroda T, Nakamura Y, Zembutsu H. Pharmacogenomics of tamoxifen: roles of drug metabolizing enzymes and transporters. Drug Metab Pharmacokinet 2012; 27: 122-131, doi: 10.2133/dmpk.DMPK-11-RV-084.

7. Stearns V, Johnson MD, Rae JM, Morocho A, Novielli A, Bhargava $\mathrm{P}$, et al. Active tamoxifen metabolite plasma concentrations after coadministration of tamoxifen and the selective serotonin reuptake inhibitor paroxetine. $J$ Natl Cancer Inst 2003; 95: 1758-1764, doi: 10.1093/jnci/djg108.

8. Goetz MP, Rae JM, Suman VJ, Safgren SL, Ames MM, Visscher DW, et al. Pharmacogenetics of tamoxifen biotransformation is associated with clinical outcomes of efficacy and hot flashes. J Clin Oncol 2005; 23: 9312-9318, doi: 10.1200/JCO.2005.03.3266.

9. Nowell SA, Ahn J, Rae JM, Scheys JO, Trovato A, Sweeney $C$, et al. Association of genetic variation in tamoxifenmetabolizing enzymes with overall survival and recurrence of disease in breast cancer patients. Breast Cancer Res Treat 2005; 91: 249-258, doi: 10.1007/s10549-004-7751-x.

10. Regan MM, Leyland-Jones B, Bouzyk M, Pagani O, Tang W, Kammler R, et al. CYP2D6 genotype and tamoxifen response in postmenopausal women with endocrineresponsive breast cancer: the breast international group 198 trial. J Natl Cancer Inst 2012; 104: 441-451, doi: 10.1093/ jnci/djs125.

11. Wegman PP, Wingren S. CYP2D6 variants and the prediction of tamoxifen response in randomized patients: author response. Breast Cancer Res 2005; 7: E7, doi: 10.1186/bcr1326. confirm this association.

We conclude that patients with reduced CYP2D6 activity did not present worse tumor characteristics or reduced DFS than women with normal enzymatic activity as the differences were not statistically significant. We observed a high frequency of CYP2D6 *10, which had not been previously described in this population.

\section{Acknowledgments}

A special thanks to the patients who agreed to participate in this study. Research supported by CAPES.

12. Okishiro $M$, Taguchi $T$, Jin $K S$, Shimazu K, Tamaki $Y$, Noguchi S. Genetic polymorphisms of CYP2D6 10 and CYP2C19 2, 3 are not associated with prognosis, endometrial thickness, or bone mineral density in Japanese breast cancer patients treated with adjuvant tamoxifen. Cancer 2009; 115: 952-961, doi: 10.1002/cncr.24111.

13. Toyama $T$, Yamashita $H$, Sugiura $H$, Kondo $N$, Iwase $H$, Fujii Y. No association between CYP2D6*10 genotype and survival of node-negative Japanese breast cancer patients receiving adjuvant tamoxifen treatment. Jpn J Clin Oncol 2009; 39: 651-656.

14. Jardim D.L.F, Katz A. Determination of the frequency of CYP2D6 polymorphisms in Brazilian women and literature review. Rev Bras Mastol 2014; 20: 55.

15. Antunes MV, Linden R, Santos TV, Wallemacq $P$, Haufroid $\mathrm{V}$, Classen JF, et al. Endoxifen levels and its association with CYP2D6 genotype and phenotype: evaluation of a southern Brazilian population under tamoxifen pharmacotherapy. Ther Drug Monit 2012; 34: 422-431.

16. Hoskins JM, Carey LA, McLeod HL. CYP2D6 and tamoxifen: DNA matters in breast cancer. Nat Rev Cancer 2009; 9: $576-586$, doi: $10.1038 / \mathrm{nrc} 2683$.

17. Ingelman-Sundberg M. Genetic polymorphisms of cytochrome P450 2D6 (CYP2D6): clinical consequences, evolutionary aspects and functional diversity. Pharmacogenomics J 2005; 5: 6-13.

18. Schur BC, Bjerke J, Nuwayhid N, Wong SH. Genotyping of cytochrome P450 2D6*3 and *4 mutations using conventional PCR. Clin Chim Acta 2001; 308: 25-31, doi: 10.1016/ S0009-8981(01)00422-3.

19. Kiyotani K, Mushiroda T, Sasa M, Bando Y, Sumitomo I, Hosono $\mathrm{N}$, et al. Impact of CYP2D6*10 on recurrence-free survival in breast cancer patients receiving adjuvant tamoxifen therapy. Cancer Sci 2008; 99: 995-999, doi: 10.1111/ j.1349-7006.2008.00780.x

20. Rae JM, Goetz MP, Hayes DF, Ingle JN, Li L, Storniolo AM, et al. CYP2D6 genotype and tamoxifen response. Breast Cancer Res 2005; 7: E6, doi: 10.1186/bcr1297.

21. Wegman P, Vainikka L, Stal O, Nordenskjold B, Skoog L, Rutqvist LE, et al. Genotype of metabolic enzymes and the benefit of tamoxifen in postmenopausal breast cancer patients. Breast Cancer Res 2005; 7: R284-R290, doi: 10.1186/bcr993.

22. Park IH, Ro J, Park S, Lim HS, Lee KS, Kang HS, et al. Lack 
of any association between functionally significant CYP2D6 polymorphisms and clinical outcomes in early breast cancer patients receiving adjuvant tamoxifen treatment. Breast Cancer Res Treat 2013; 131: 455-461, doi: 10.1007/s10549011-1425-2.

23. Tamm E, Kivisild T, Reidla M, Metspalu M, Smith DG, Mulligan CJ, et al. Beringian standstill and spread of Native American founders. PLoS One 2007; 2: e829, doi: 10.1371/ journal.pone.0000829.

24. Fagundes NJ, Ray N, Beaumont M, Neuenschwander S, Salzano FM, Bonatto SL, et al. Statistical evaluation of alternative models of human evolution. Proc Natl Acad Sci U S A 2007; 104: 17614-17619, doi: 10.1073/pnas.0708280104.

25. Gonzalez-Jose R, Bortolini MC, Santos FR, Bonatto SL. The peopling of America: craniofacial shape variation on a continental scale and its interpretation from an interdisciplinary view. Am J Phys Anthropol 2008; 137: 175-187, doi: 10.1002/ajpa.20854.

26. Jorge LF, Eichelbaum M, Griese EU, Inaba T, Arias TD. Comparative evolutionary pharmacogenetics of CYP2D6 in Ngawbe and Embera Amerindians of Panama and Colombia: role of selection versus drift in world populations. Pharmacogenetics 1999; 9: 217-228.

27. Isaza CA, Henao J, Lopez AM, Cacabelos R. Isolation, sequence and genotyping of the drug metabolizer CYP2D6 gene in the Colombian population. Methods Find Exp Clin Pharmacol 2000; 22: 695-705, doi: 10.1358/mf.2000.22.9. 802286.

28. Salazar-Flores J, Torres-Reyes LA, Martinez-Cortes G, RubiCastellanos R, Sosa-Macias M, Munoz-Valle JF, et al. Distribution of CYP2D6 and CYP2C19 polymorphisms associated with poor metabolizer phenotype in five Amerindian groups and western Mestizos from Mexico. Genet Test Mol Biomarkers 2012; 16: 1098-1104, doi: 10.1089/gtmb.2012. 0055.

29. Bradford LD. CYP2D6 allele frequency in European Caucasians, Asians, Africans and their descendants. Pharmacogenomics 2002; 3: 229-243, doi: 10.1517/14622416.3.2. 229.

30. Silveira VS, Canalle R, Scrideli CA, Queiroz RG, Tone LG. Polymorphisms in genes encoding drugs and xenobiotic metabolizing enzymes in a Brazilian population. Biomarkers 2009; 14: 111-117, doi: 10.1080/13547500902767294.

31. Wennerholm A, Dandara C, Sayi J, Svensson JO, Abdi YA, Ingelman-Sundberg M, et al. The African-specific CYP2D617 allele encodes an enzyme with changed substrate specificity. Clin Pharmacol Ther 2002; 71: 77-88, doi: 10.1067/mcp.2002. 120239. 